\title{
O silêncio em quatro interpretações
}

Adilson Citelli ${ }^{1}$

Professor livre-docente no Departamento de Comunicações e Artes da ECA-USP e chefe do Departamento de Comunicações e Artes.

E-mail: citelli@uol.com.br

Em meio à ruidosa sociedade contemporânea, a necessidade de um momento de silêncio é tão imprescindível quanto foi nos tempos passados. Permanecer em silêncio nos permite escutar as vozes de nossos pensamentos, e nesse momento especial, os sentidos transmitem à mente toda espécie de sensações, sejam de dor, sejam de prazer. O silêncio é múltiplo, manifesta sua particularidade em cada alma. É o momento da ponderação e da reflexão, é o complemento de pensamentos intraduzíveis, é o medo da exposição, é a espera do momento oportuno, é o puro consentimento ou a total negação, é o inexprimível. E como alcançar o inexprimível? Alguns escritores manifestaram sua singularidade através da difícil tarefa de expressar por palavras, ou de até mesmo ritmar, o silêncio. Selecionamos quatro grandes escritores brasileiros que, de distintas maneiras, colocaram o silêncio como elemento de seus poemas. Para Carlos Drummond de Andrade, o silêncio é força propulsora da poesia; João Cabral de Melo Neto o define como uma substância que assume diferentes formas, passando do pesado ao levíssimo; para Manuel Bandeira, é lírico; e, finalmente, para Murilo Mendes, o "homem de Castela" é moldado pelo silêncio. Desejamos que esta seleção de poemas possa servir para cada leitor encontrar um significado para seu próprio silêncio.

\section{CARLOS DRUMMOND DE ANDRADE}

Carlos Drummond de Andrade nasceu em Itabira, Minas Gerais, em 31 de outubro de 1902, em uma família de fazendeiros em decadência. Começou a carreira de escritor como colaborador do Diário de Minas, que reunia os adeptos do movimento modernista mineiro. Concluiu o curso de Farmácia na cidade de Ouro Preto, em 1925. Fundou, ao lado de outros escritores, A Revista, um importante veículo do modernismo em Minas Gerais. Sua estréia na literatura ocorreu em 1930, com Alguma Poesia.

Durante a maior parte da vida foi funcionário público. Morreu no Rio de Janeiro, em 1987. Várias obras do poeta foram traduzidas para o espanhol, inglês, francês, italiano, alemão, sueco, tcheco e outras línguas. A obra de Carlos Drummond de Andrade continua sendo uma das mais importantes da literatura brasileira.

1. Com a colaboração de Cristine Vargas (revista Comunicação \& Educação - ECA/USP e FFLCH/USP). 


\section{Procura da poesia}

Não faças versos sobre acontecimentos.

Não há criação nem morte perante a poesia.

Diante dela, a vida é um sol estático,

não aquece nem ilumina.

As afinidades, os aniversários, os incidentes pessoais não contam.

Não faças poesia com o corpo,

esse excelente, completo e confortável corpo, tão infenso à efusão lírica.

Tua gota de bile, tua careta de gozo ou dor no escuro

são indiferentes.

Não me reveles teus sentimentos,

que se prevalecem de equívoco e tentam a longa viagem.

$\mathrm{O}$ que pensas e sentes, isso ainda não é poesia.

Não cantes tua cidade, deixa-a em paz.

O canto não é o movimento das máquinas nem o segredo das casas.

Não é música ouvida de passagem, rumor do mar nas ruas junto à linha de espuma.

O canto não é a natureza

nem os homens em sociedade.

Para ele, chuva e noite, fadiga e esperança nada significam.

A poesia (não tires poesia das coisas)

elide sujeito e objeto.

Não dramatizes, não invoques,

não indagues. Não percas tempo em mentir.

Não te aborreças.

Teu iate de marfim, teu sapato de diamante,

vossas mazurcas e abusões, vossos esqueletos de família

desaparecem na curva do tempo, é algo imprestável.

Não recomponhas

tua sepultada e merencória infância.

Não osciles entre o espelho e a

memória em dissipação.

Que se dissipou, não era poesia.

Que se partiu, cristal não era.

Penetra surdamente no reino das palavras.

Lá estão os poemas que esperam ser escritos.

Estão paralisados, mas não há desespero,

há calma e frescura na superfície intata.

Ei-los sós e mudos, em estado de dicionário.

Convive com teus poemas, antes de escrevê-los. 
Tem paciência se obscuros. Calma, se te provocam.

Espera que cada um se realize e consume

com seu poder de palavra

e seu poder de silêncio.

Não forces o poema a desprender-se do limbo.

Não colhas no chão o poema que se perdeu.

Não adules o poema. Aceita-o

como ele aceitará sua forma definitiva e concentrada

no espaço.

Chega mais perto e contempla as palavras.

Cada uma

tem mil faces secretas sob a face neutra

e te pergunta, sem interesse pela resposta,

pobre ou terrível, que lhe deres:

Trouxeste a chave?

Repara:

ermas de melodia e conceito

elas se refugiaram na noite, as palavras.

Ainda úmidas e impregnadas de sono,

rolam num rio difícil e se transformam em desprezo.

\section{JOÃO CABRAL DE MELO NETO}

João Cabral de Melo Neto nasceu na cidade de Recife, Pernambuco, em 9 de janeiro de 1920. Até os 10 anos, viveu em engenhos de açúcar em São Lourenço da Mata e Moreno, na Zona da Mata pernambucana. Era primo, pelo lado paterno, de Manuel Bandeira e, pelo lado materno, de Gilberto Freyre. Em 1940, viajou com a família para o Rio de Janeiro, onde conheceu Murilo Mendes, que o apresentou a Carlos Drummond de Andrade e ao círculo de intelectuais que se reunia no consultório de Jorge de Lima. Em 1942, publicou seu primeiro livro, Pedra do Sono, e, em 1945, O Engenheiro. Fez concurso para a carreira diplomática, trabalhando durante a maior parte de sua carreira na Espanha, local que o influenciou fortemente.

Sua obra tornou-se mais conhecida quando, em 1965, o grupo de Teatro da Universidade Católica - TUCA encenou em São Paulo Morte e Vida Severina. Foi eleito para a Academia Brasileira de Letras em 1968. Em 1990, tornou-se o primeiro brasileiro a receber o Prêmio Camões, patrocinado conjuntamente pelos governos do Brasil e de Portugal. Aposentou-se como embaixador no mesmo ano e também publicou Sevilha Andando. Dois anos depois, recebeu o Neustadt International Prize for Literature, da Universidade de Oklahoma, Estados Unidos. João Cabral de Melo Neto sofria de uma doença degenerativa incurável que fez sua visão desaparecer aos poucos. Faleceu no dia 9 de outubro de 1999, no Rio de Janeiro. 


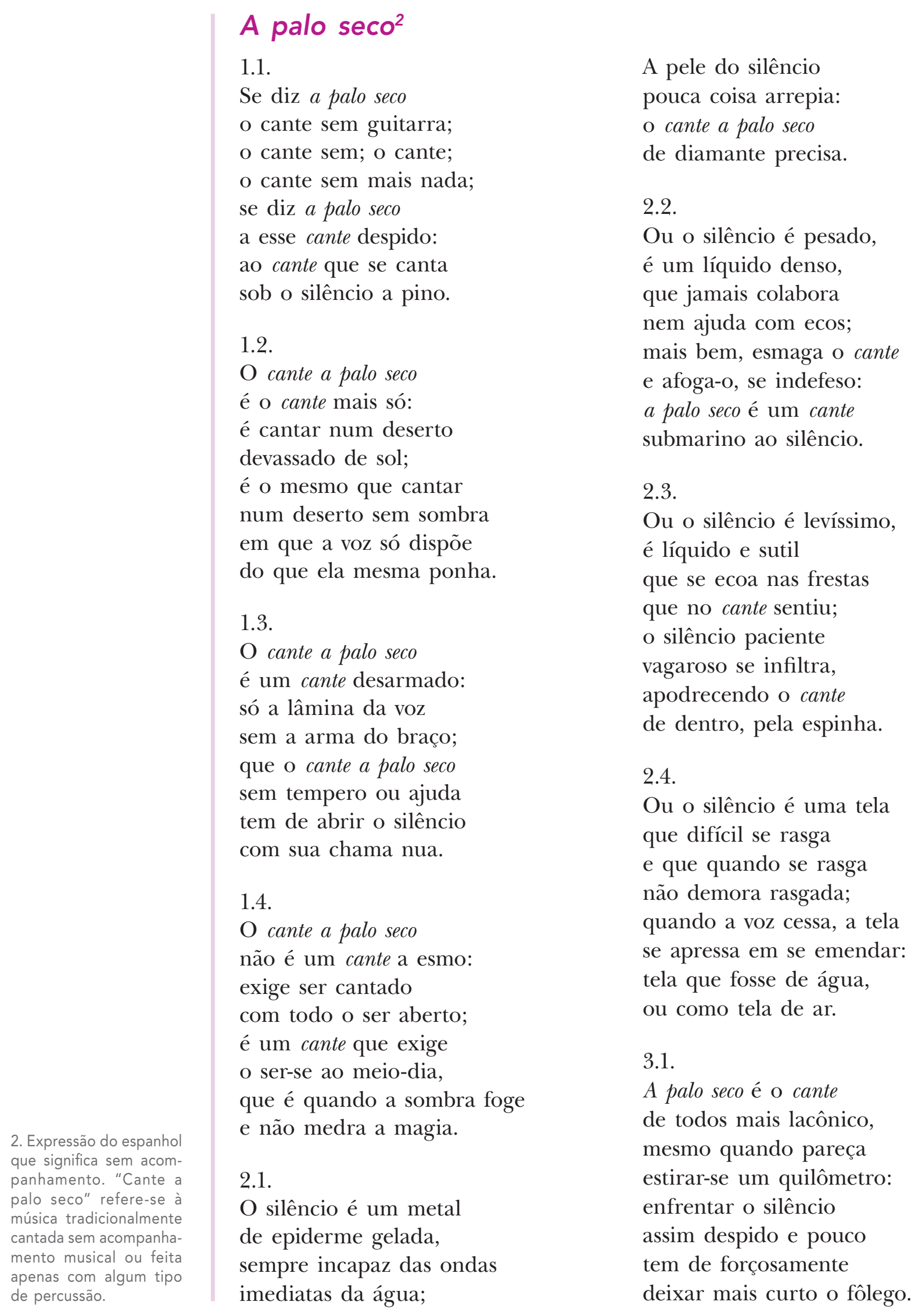


3.2.

A palo seco é o cante

de grito mais extremo:

tem de subir mais alto

que onde sobe o silêncio;

é cantar contra a queda,

é um cante para cima,

em que se há de subir

cortando, e contra a fibra.

3.3.

A palo seco é o cante

de caminhar mais lento:

por ser a contra-pelo, por ser a contra-vento;

é cante que caminha

com passo paciente:

o vento do silêncio

tem a fibra de dente.

3.4.

A palo seco é o cante que mostra mais soberba;

e que não se oferece:

que se toma ou se deixa;

cante que não se enfeita,

que tanto se lhe dá;

é cante que não canta, cante que aí está.

\section{1.}

A palo seco canta

o pássaro sem bosque, por exemplo: pousado

sobre um fio de cobre; a palo seco canta

ainda melhor esse fio

quando sem qualquer pássaro

dá o seu assovio.

4.2.

A palo seco cantam

a bigorna e o martelo,

o ferro sobre a pedra

o ferro contra o ferro;

a palo seco canta

aquele outro ferreiro:

o pássaro araponga

que inventa o próprio ferro.

4.3.

A palo seco existem

situações e objetos:

Graciliano Ramos,

desenho de arquiteto,

as paredes caiadas,

a elegância dos pregos,

a cidade de Córdoba,

o arame dos insetos.

4.4

Eis uns poucos exemplos

de ser a palo seco,

dos quais se retirar

higiene ou conselho:

não o de aceitar o seco

por resignadamente,

mas de empregar o seco

porque é mais contundente.

\section{MANUEL BANDEIRA}

Manuel Carneiro de Souza Bandeira Filho nasceu no Recife no dia 19 de abril de 1886. Em 1903, sua família mudou-se para São Paulo, onde Manuel Bandeira se matriculou na Escola Politécnica, pretendendo formar-se arquiteto. No final do ano de 1904, o autor, ao saber que estava tuberculoso, abandonou suas atividades e mudou-se para o Rio de Janeiro. Escreveu seus primeiros versos livres, em 1912. A Cinza das Horas, seu primeiro livro, foi publicado em 1917. No 
comunicação \& educação • Ano XIII • Número 3 • set/dez 2008

ano seguinte, faleceu a irmã Maria Cândida de Souza Bandeira, que havia sido sua dedicada enfermeira. Em 1919, publicou seu segundo livro, Carnaval.

Em 1922, começou a se corresponder com Mário de Andrade. Manuel Bandeira não participou da Semana de Arte Moderna, realizada em fevereiro em São Paulo, no Teatro Municipal; entretanto, na ocasião, Ronald de Carvalho leu o poema Os Sapos, do livro Carnaval. Em 1936, grandes comemorações marcaram os 50 anos do poeta, entre as quais a publicação de Homenagem a Manuel Bandeira, livro com poemas, estudos críticos e comentários, de autoria dos principais escritores brasileiros da época. No mesmo ano publicou Estrela da Manhã e Crônicas da Província do Brasil. Em 1940, foi eleito para a Academia Brasileira de Letras, na vaga de Luís Guimarães Filho. Publicou Poesias Completas, com a inclusão da Lira dos Cinqüent'Anos.

Comemorou seus 80 anos, em 1966, recebendo muitas homenagens. A Editora José Olympio promoveu o lançamento dos volumes Estrela da Vida Inteira (poesias completas e traduções de poesia) e Andorinha Andorinha (seleção de textos em prosa, organizada por Carlos Drummond de Andrade). Manuel Bandeira faleceu no dia 13 de outubro de 1968, no Rio de Janeiro.

\section{O silêncio}

Na sombra cúmplice do quarto,

Ao contacto das minhas mãos lentas

A substância da tua carne

Era a mesma que a do silêncio.

Do silêncio musical, cheio

De sentido místico e grave,

Ferindo a alma de um enleio

Mortalmente agudo e suave.

Ah, tão suave e tão agudo!

Parecia que a morte vinha...

Era o silêncio que diz tudo

O que a intuição mal adivinha.

É o silêncio da tua carne.

da tua carne de âmbar, nua,

Quase a espiritualizar-se

$\mathrm{Na}$ aspiração de mais ternura.

\section{MURILO MENDES}

Murilo Monteiro Mendes nasceu no dia 13 de maio de 1901, em Juiz Fora, Minas Gerais. Aos 16 anos fugiu do colégio para assistir, no Rio de Janeiro, 
à apresentação do bailarino e coreógrafo russo Vaslav Nijinski. Nessa mesma época, recusou-se a continuar os estudos. Em 1920, após várias tentativas da família de estabelecê-lo num emprego, vai, com o irmão mais velho, para o Rio de Janeiro. Durante os anos de 1924 a 1929, o autor dedicou-se à formação cultural. Nesse período, foi arquivista no Ministério da Fazenda e funcionário do Banco Mercantil. Publicou poemas em revistas modernistas como Verde e Revista de Antropofagia.

Seu primeiro livro, Poemas, foi publicado em 1930. Converteu-se ao catolicismo em 1934, fato que influencia fortemente seu segundo livro, Tempo e Eternidade, publicado no ano seguinte. Mudou-se para a Itália em 1957, onde se tornou professor de Cultura Brasileira na Universidade de Roma. Foi também professor na Universidade de Pisa. Seus livros foram publicados por toda a Europa. Em 1972, recebeu o prêmio internacional de poesia Etna-Taormina. Murilo Mendes faleceu em Lisboa, no dia 13 de agosto de 1975 .

\section{Homenagem a Cervantes}

$\mathrm{Na}$ estepe de Castela o homem mede a sede,

Mede o sol, desdém e força.

Na estepe de Castela

O homem mede suas malandanças,

Caminha com a rudeza a tiracolo.

$\mathrm{Na}$ estepe de Castela

Campos desnudos, vento e argila,

Céu côncavo, cifrado,

Determinam o espaço substantivo,

O estilo do silêncio:

E o silêncio cria o homem de Castela.

Armado por cinqüenta anos de silêncio

Teu herói marcha com seu escudeiro

Que não é seu duplo hostil ou lado oposto,

Antes parte integrante de si mesmo.

Não precisou marchar além da Espanha.

Ao alcance da mão temos o homem, o mundo,

Mesmo medidos num espaço angusto.

Paralelamente, no teu livro total

Se como terrestre experiência.

No espaço e na medida de Castela,

Na solidão do ar absoluto de Castela

Distingui minha medida temporal. 
O homem foi criado para se conhecer circunscrito, Seus ângulos e arestas o definem. Castela interior que me demarcas, Correspondes à outra Castela clássica, Ameaçada Castela: aqui a indústria Já inaugura sua máquina indiscreta.

Mas, se deve nutrir teus homens secos, Que venha e permaneça a máquina indiscreta:

Frente ao excesso mecânico da técnica,

Frente a moinhos com radar, Dulcinéias de vidro, armaduras atômicas, Responderá o equilíbrio de Cervantes.

\section{REFERÊNCIAS BIBLIOGRÁFICAS}

ANDRADE, Carlos Drummond de. A rosa do povo. In: Poesia completa. Rio de Janeiro: Nova Aguilar, 2004.

BANDEIRA, Manuel. O ritmo dissoluto. In: Poesia completa e prosa. Rio de Janeiro: Nova Aguilar, 1996.

MELO NETO, João Cabral de. Quaderna. In: Poesias completas. Rio de Janeiro: Sabiá, 1975.

MENDES, Murilo. Tempo espanhol. In: Poesia completa e prosa. Rio de Janeiro: Nova Aguilar, 1994.

\section{Endereços eletrônicos}

$<$ http://www.releituras.com/biografias.asp >

$<$ http://www.itaucultural.org.br/aplicexternas/enciclopedia\%5Flit/> 